\title{
A Cultural Psychological Reading of Dalit Literature:A Case Study of Joothan by Om Prakash Valmiki
}

\author{
Aparna Vyas'
}

\begin{abstract}
Dalit literature has been a major cultural artefact in struggles against castebased oppression and discrimination. It not only negotiates a collective identity for Dalits but also introduces variability in negotiations for the same. This paper focuses on the nuances of one such negotiation- the making of a Hindi Dalit writer. At the theoretical backdrop of cultural psychology, utilizing the conceptual machinery of Zittoun, the paper analyzes the autobiographical narrative of Om Prakash Valmiki. It identifies the ruptures and the transitional processes in Valmiki's life. These processes of transitions include identity redefinition, knowledge and skills; and meaning making. These processes were facilitated by varied resources: social, cognitive and symbolic. Valmiki's relocation to a city led to the change in his frame of activity. Thereafter, at each stage of his life, his social circle widened, his cognitive skills got enhanced and symbolic resources were used at progressively higher level of reflexivity. The major social resources were found to be the people with whom he came in contact after relocating to the city. The cognitive resources were found to be Hindi mainstream literature, Marathi Dalit literature, and theatrical devices. The symbolic resources were the works of Phule, Ambedkar and Marx. Accessibility and utilization of all these resources eased the reconfiguration of the semiotic prism reifying his identity as a Hindi Dalit writer enabling him transform the caste-based experiences on the plane of fiction challenging the power hierarchy embedded in social reality.
\end{abstract}

\section{Keywords}

Dalit literature, Valmiki, Joothan, dalit expression, caste

\footnotetext{
'Doctoral Scholar, Zakir Husain Centre for Educational Studies, Jawaharlal Nehru University, New Delhi, India

E-mail:a02.vyas@gmail.com
}

(C) 2020 Aparna Vyas. This is an open access article distributed under the terms of the Creative Commons Attribution License, which permits unrestricted use, distribution, and reproduction in any medium, provided the original author(s) and source are credited. 


\section{Introduction}

The word Dalit captures the collective struggle against the caste based hierarchy and oppression associated with it. It encapsulates the collective emotion of anguish resulting from being downtrodden for centuries in the name of rituals and traditions associated with religion. Drawing vitality from the teachings of Dr. B.R. Ambedkar, Dalit literature is the expression of the dissatisfaction that Dalit writers have had with the so-called upper caste writers who never took discriminatory practices into account as 'rarely did a writer take up an untouchable character and treat him realistically, like an ordinary human being full of vitality, hope as well as despair' (Kumar, 2010, p.129). Their experiences of marginalization in almost every sphere of life made Dalit writers assert their opinions which found creative expression in the form of almost every genre of literaturepoems, stories, folklore, dramas and non-fiction.

The present paper focuses on one of those excruciatingly painful account of experiences penned down by renowned Hindi Dalit writer, Om Prakash Valmiki. His autobiographical account Joothan (Leftover) analyzed here is laden with the anguish as well as anger resulting from rampant caste based discrimination and exclusion. Sadly, this literature of resistance has been subjected to the same exclusion and undermined using several parameters. It has been accused of being propagandist, univocal and resentful in nature, and is disregarded on the universal standards of artistic finesse, neutrality and objectivity (Limbale, 2004). Critics posing these questions to Dalit literature, as discussed by Valmiki (2001) fall into three categories. The first group includes those who negate the overall existence of Dalit literature. The second group objects the authorship and ownership of Dalits over literature and holds the view that non-Dalits can also write Dalit literature. The third group comprises those Dalit critics who consider it inappropriate to bring out the experiential life of Dalits as part of public discourse.

As a fitting rejoinder to these critics, Dalit writers have set their standards for the aesthetics of Dalit literature. They have focused on the notion of art for life sake instead of art for art sake and define it 'as literature which artistically portrays the sorrows, tribulations, slavery, degradation, ridicule and poverty endured by Dalits' (Limbale, 2004, p.30). Since the word Dalit encompasses the suffering of all those who have been subjected to humiliation and injustice pertaining to caste, class, and gender, so the literary standards to evaluate this literature should be based on the theory capable of capturing social justice as its essence rather than the yardstick of entertainment and beauty.

Dalit literature voices experiences of the constant search of the self-respect while attacking the traditions set against this search. It questions the established criteria of neutrality and objectivity. It rejects the maxim of Satyam, Shivam Sundaram (Truth, Godliness and Beauty) ${ }^{3}$ and seeks to see life in its untruth, unholy and unbeauty of reality from the vantage points of a Dalit (Ibid).

Writing in the same vein, Valmiki (2001) underlines Premchand's incapability to capture the lived realities of Dalits as he constantly portrays them as hapless victims drawing extensively on the metaphors, phrases, and language representing the upper caste mind-set. He also puts to scrutiny the Sanskrit and western literary conventions which are considered the very origins of aesthetic tradition in Hindi literature, and further stresses the inability of these forced conventions in portraying the essence 
and specificities of Dalit lives and doing justice with the linguistic, metaphorical, and emotional foundations of Dalit literature (Ibid).

Pointing out the time and context bound nature of literature, Limbale (2004) writes, 'The act of imagination called art is impermanent and ever changing. Literature changes with changing culture. Unless the yardsticks change, the relationship between literature and criticism will be fractured' (p.107). And Valmiki (2001) restores this relationship between Dalit literature and its criticism by combining the tenets of Ambedkarism and Marxism representing caste and class consciousness respectively. He also lays down the key elements of Dalit chetna (consciousness) based on the vision of Ambedkar, rejecting Ram Chandra Shukla's definition of a great poetry.

In an effort to extend an interdisciplinary understanding into Dalit literature, the present paper is an attempt to analyze the text through the prism of psychology. It has two sections: the first includes reflexivity statement, a discussion on the theoretical framework and method of analysis. The second section presents the analysis of Joothan into different frames of activity. The paper argues that a Dalit autobiography analyzed from the semiotic prism of cultural psychology unfolds a much nuanced account of the making of a Dalit writer embedded in specific socio-cultural and historical milieu.

\section{Reflexivity Statement}

Born and brought up in a relatively socially-privileged household, I was introduced to Dalit literature as a student of Educational studies. My first reading in Dalit literature was an English translation of Akkarmashi(The Outcaste) by Sharan Kumar Limbale which led me to sleepless nights and restless days. For the first time I could understand the idea of caste beyond its constitutionally recognized categories. As a student of psychology in graduation and post-graduation, I reviewed studies on caste but majority of those treated caste merely as a variable and not as an experiential reality of the Indian society. Such reduction of caste into a variable which can be easily manipulated, balanced, and controlled, if the researcher is 'not interested' in observing its impact, is informed by and based on 'the two world problem: Out there vs. In here'. These two worlds are 'psychological world of the self (which perceives, deliberates and decides), and at the same time a material world (that which exists outside our thoughts)' (Gergen,1999, p. 8).

Deletion of such narratives from the academic field and the disturbing silence of psychology, specifically when it comes to the theorization of caste, regarding these issues are even more disquieting.

Against the theoretical backdrop of cultural psychology, the present paper is my reading of Joothan by Om Prakash Valmiki. The purpose of presenting the reading as a case study is to chart out a way how a Dalit life-narrative can be analyzed psychologically, bringing forth the transformation of a boy who was subjected to caste-based atrocities into a notable Dalit writer who wrote resistance. People may read the autobiography from varied lenses and the reading presented here is one of the innumerable possibilities that narratives of resistance have to offer. I have attempted to read this narrative against the backdrop of my disciplinary capabilities. 


\section{Theoretical Framework and Method}

Cultural psychology lays emphasis on the mutual constitution of mind and culture, the process of meaning making, and the mediational nature of cognitive processes. It does not reduce culture into an entity or,

"a "thing" that one "has", or "gets" (by assimilation or socialization), but the active process of mediating human lives through signs, both intra- and interpsychologically. The central issue for cultural psychology is to locate culture in the life activities of agentive persons. These persons are meaning makers, and the meaning made frame their relations with the environment.' (Valsiner, 2014, p.47-48)

Under the broader theoretical framework of cultural psychology, the paper utilizes the conceptual machinery of Zittoun (2007a, 2007b, 2008). The unit of analysis is rupture- transition. Ruptures here refer to the events and situations of life that pose a challenge for the taken for granted reality of an individual. They are considered psychologically significant only when the individual concerned perceives them as such. These are analyzed after the levels of explanation of the world given by Doise (as cited in Zittoun, 2007a) as related to 'intra-psychic, interpersonal relationships, one's relationship to a social group or to a societal state' (Ibid, p.351). They are followed by the processes of transition - 'through which the person engages in restoring some sense of personal integrity, regularity, and continuity, and reduces uncertainty' (Ibid, p.348). The processes of transition include three interdependent processes- identity redefinition, knowledge and skills, and meaning making. Each of this process of transition is facilitated by specific resources. An individual mobilizes social resources (mobilization of the social networks and social knowledge) in order to aid the process of identity redefinition. In the same way, cognitive resources assist the process of learning. The third kind of resources is symbolic resources which facilitate the process of meaning making. Symbolic resources refer to how people make use of cultural artefacts or elements as developmental resources in the face of situations loaded with uncertainty (Zittoun, 2007b). Three important conditions that she delineates for any cultural element to be considered a symbolic resource are the following.

1. Intentional use of the cultural element at least partially deviant from its 'aboutness'.

2. Use of the cultural element should be 'beyond the immediate cultural value and meaning of that cultural element' (Zittoun, 2007a, p.344).

3. Inclusion of cultural elements "that require an "imaginary" experience-the creation of a sphere of experience beyond here and now of the socially shared reality' (Ibid).

Symbolic resources mediate in the three basic psychological processes: intentionality, inscription in time, and distancing. About intentionality, Zittoun writes, 'Symbolic resources are cultural elements which, when used by the person, become about something else with some intention' (Ibid, p.346). The use of symbolic resources is located in time and 'the knitting of past and future into the present' is required for their use. Besides, each successive level of distancing represents the experience in a distant manner- from an embodied state, to contained and fixed emotional patterns; from those, to a labeled situation; from the latter, to categories grouping various experiences of self and the world; and from categories to orienting values. 'Symbolic resources offer such distancing possibility, because they create an imaginary sphere where personal, unique experiences meet culturally elaborated versions of other people's comparable 
experiences (Ibid,p.348). They are generative in nature when used 'across a wide range of modality of uses'. They enhance or transform the understanding of the individual about self, about other and about the world as well.

The use of these resources is reflexive in nature. Here the dimension of usage ranges from degree zero use to the reflective use. Degree zero use is related with the simple appreciation of a cultural element. In quasi use, the individual possesses a vague sense that using that cultural element actually affects him/her. During intuitive use, the individual may not be clearly conscious about it still they acknowledge the effects of having specific cultural experience. Deliberate and reflective usage entails the active search for a cultural element to use it as a resource,reflection about the potential uses of the cultural element and the changes resulting from the utilization of the element (Ibid, p.354).

The process of transitions is represented through the semiotic prism having the four corners representing the subject, the other, the symbolic object, and the subject's sense of symbolic object. The model addresses both the intrapersonal and interpersonal dynamics. The former ones are represented by the vector between the person and the person's-sense-of-the-object and the latter ones are represented by the person-to-other and person-to-object-vectors (Zittoun, 2008). The semiotic prisms (Figure1 and 2) depicted in the present paper are based and adapted from this framework. (Ibid, p.168).

The semiotic prism is located within the specific setting called a frame of activity for the individual. The concept of frame stands for the larger societal context where social interactions take place. Therefore:

Change can be seen as linked to the reconfiguration of the elements constitutive of the semiotic prism, and of their respective relationships- a change of the relationship of the person towards the other, the transformation of the sense of situation for the person, and consequently, of the object for him/her. Through such reconfigurations, something radically new can also emerge. (Zittoun, 2008, p. 16)

The paper intends to work with the said conceptual machinery to thematically analyze the autobiography of Om Prakash Valmiki. For the purpose of analysis, Valmiki's autobiography Joothan has been divided in two parts: before relocation and after relocation. Relocations here signify the changing pattern of the dialectical relationship between Valmiki and his environment. The phase preceding relocation marks the predominance of environment over the agency, but in the life after relocation the agency occupies centre stage.

In brief, the analysis of Vlamiki's autobiography focuses on these questions Was there a rupture in the experiential life of Valmiki? If yes, what was it and did it lead to transitions? What were the processes of transitions and what were the resources at hand that were utilized to facilitate these transitions?

\section{Before Relocation: Village as the Frame of Activity}

Being the youngest and the most pampered child of his family, Valmiki was always encouraged to study by his parents and family members. His father, especially, had been very supportive in this regard because he believed that education was the only means by which caste can be 'improved'. Valmiki received his primary education from Sewak Ram Masihi who used to teach children of Chuhra's (sweeper) community in his neighbourhood. As Valmiki recalls, 'I learnt my alphabet in Master Sewak Ram 
Masihi's open air school, a school without mats or rooms' (Valmiki, 2003, p.2). In this school 'without mats and rooms', he didn't mention a single sign of discrimination.

An argument between his father and the teacher, Masihi (of whom Valmiki does not give any account), made his father get Valmiki enrolled to the Basic Primary School by requesting Master Harphool Singh, 'Masterji, I'll be forever in your debt if you teach this child of mine a letter or two' (Ibid, p.3). In the new school, however, Valmiki faced caste-based discrimination that he describes in detail. He was made to sweep the whole school which was an unusual work for him: 'I swept the whole day. I had never done so much work being (the) pampered one among my brothers' (Ibid, p.5). What left a deep impression on his mind was the retaliation of his father to this maltreatment at the school and restored his confidence to some extent. Another incident that he mentions 'as life changing' was his mother's retaliation against insult inflicted on her by a Tyagi(an upper caste person). Both these incidents worked as an illuminating force in Valmiki's life which was darkened by caste oppression from an early age. Due to the weak financial condition of his family, he could not get admission to school after fifth standard. 'There was no question of taking admission given the circumstances the family found itself in. How could one think of studies when one didn't even have food' (Ibid, p.14). At this juncture, his bhabhi(sister-in-law) came to his rescue and offered her only ornament to sell and pay for his studies.

He did make progress in his studies. 'I had stood first in my section in the halfyearly exam. My results bolstered my self-confidence. I was made the class monitor after the examination and my seat was moved from the back of the class to the front' (Ibid, p.17). Despite his great academic performance, he was constantly discriminated in school which was not only limited to preventing him from participating in extracurricular activities. Rather,

All the teachers were Tyagis, and among the students too Tyagis were in majority.

No one could afford to say anything against them. During the examination we could not drink water from a glass when thirsty. To drink water, we had to cup our hands. The peon would pour water from way high up, lest our hands touch the glass. (Ibid, p.19)

Caste based discrimination affected his adjustment outside school as well. Literature was the means to get solace amidst all this. He borrowed books from the school library and read them to his mother. He was greatly influenced by the character of Saratchandra. Gradually, reading became his passion, and books his best friends. He turned into a quiet and introvert child.

The basti people used to call me the quiet one, perhaps because I did not speak as much as they did. They minded my reticence. I did not participate in their day-to day activities either. I was absorbed in my books. It was during these days that I read Premchand, Sarat Chandra, and Rabnidra Nath Tagore borrowed from the school library. I was gradually developing a taste for literature and had also begun to try my hand in verse. (Ibid, p.68)

At this stage, literature as a cultural element was used by Valmiki intuitively on the dimension of reflexivity. He was able to appreciate literature that he was reading 
(degree zero uses); also had a sense that literature had an effect on him (quasi use); and was also capable of acknowledging the effects provided by literature (intuitive use).

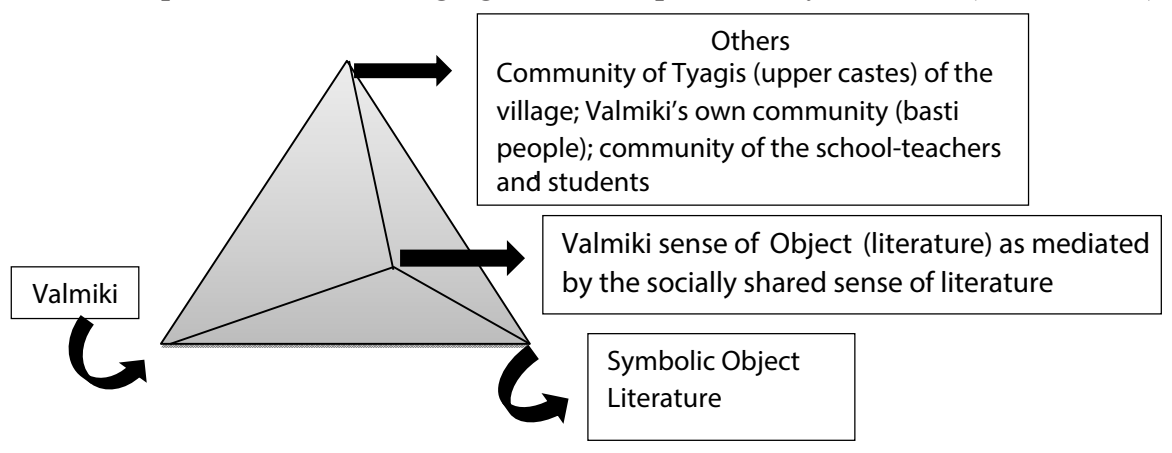

Fig. I: Semiotic Prism before Relocation

In the semiotic prism depicted in Figure 1, Valmiki has been placed at the left vertex of the prism, the 'others' are placed at the top vertex while the symbolic object, literature, has been placed at the right vertex of the prism. Valmiki's sense of literature has been denoted by the fourth vertex of the prism. Interpersonal dynamics are represented by the Valmiki-others and Valmiki-object vectors, while intrapersonal dynamics are captured by the vector which connects Valmiki with his sense of the object i.e. literature. The socially shared meaning of literature has been represented by the Valmiki-other vector and acknowledgement that he receives from others has been represented by the 'other's sense' of literature. Most importantly, the three dimensions of the transition process have been represented by; Identity by the Valmiki-other vector, knowledge by Valmiki-object vector, and meaning-making by the vector that connects Valmiki to his sense of literature.

His understanding of the cultural element can be interpreted through the semiotic prism. Based on the details provided in the autobiographical narrative, 'Other' is further divided into three categories: (i) Valmiki's own community including his family and basti people; (ii) so-called upper caste Tyagi community; and (iii) the school community including teachers and children. Such positioning of elements conveys that the socially shared meaning of literature mediated Valmiki's own understanding in it while the school setting and community had a larger role in mediating his interest in literature. Then, what is more is the contribution of Valmiki's father who despite regarding education as merely the means to 'improve' caste, was always aware of its significance. Since the village community of Valmiki was largely illiterate and Tyagis' children had greater access to schools which, in turn, subscribed to the dominant view of literature. There is no surprise that the school did not have a single reading on Ambedkar and his thoughts; and the available literature shaped the consciousness of Valmiki. Immersed in his readings, although, he cried with the characters of Saratchandra, his inner voice could not sync with experiences portrayed there. An upper caste man who was amazed at his capability to read the Ramayana (epic) and his father who was proud at his ability to read Bhagwad Gita (holy book of Hindus) could not give him any solace as no one was aware of the turmoil rooted in the conflict generated by reality which was contradictory to what was portrayed in literature. At that juncture, literature, a cultural element that he used to seek refuge in turned out to be the cause of a major intrapersonal rupture in his experiential life. He witnessed the 
abysmal apathy of people when police was mercilessly beating ten Dalit men and how literature belied the dark reality of the caste-ridden village.

Their screams had made the birds in the trees take off, but paralysis had struck the villagers, who could not express their empathy. My mind was filled with a deep revulsion. I was then an adolescent, and a scratch appeared on my mind like a line scratched on glass. It remains there still. The poem by Sumitranandan Pant that we had been taught at school, 'Ah, how wonderful is this village life'....each word of the poem had proved to be artificial and a lie. What happened that day had caused a storm inside me. (Ibid, p.45)

The rupture incurred by this discrepancy between the reality and its portrayal led him to another transitional phase when he contested against the epic Mahabharata and to question the relevance of the custom of Salam (Salute). Besides acquiring the knowledge and skills of Hindi literature, his identity was getting redefined as an educated adolescent who was observing social hierarchies and inequalities.

This intrapersonal rupture was followed by another setback. His failure in the $12^{\text {th }}$ (senior secondary) board examination disrupted the remaining continuity of life and he left the village to take admission in DAV college, Dehradun, thus, changing the frame of his activity from village to city.

\section{After Relocation: City as the Frame of Activity}

Relocation to the city forced him to make new adjustments in the midst of new challenges. He was poked fun at because of his country looks. He dealt with the mockery just by remaining quiet. Remembering those days he writes,

Since I was new in college and unfamiliar with its ways, I kept quiet. Even otherwise I was quite used to taunts and neglect. I feel amazed when I look upon those days and the things I learnt to tolerate. How much my ability to tolerate hurts flung at me had taken out of me! (Ibid, p.80)

Soon Valmiki adjusted himself to the new environment as he socialized with Surjan's friends as well as his own classmates. With the change in space of interactions, he came to know his extended family members closely and also made many friends like Bhukhanlal, Gopi, and Hemlal who were all interested in social work. The most crucial turn took place when he was given a book on Ambedkar's life in the Indresh Nagar library by his friend Hemlal. Thus, he was introduced to Ambedkar's life and struggles. He expressed what had shocked him most:

Despite my twelve years of studying in Tyagi Inter College, Barla, this name had not come to my knowledge in any way or shape. The college library also did not have a single book on Ambedkar. I had never heard this name from a teacher's or a scholar's mouth. There would be speeches on republic day when the narratives of devotion to the country were repeatedly told, but they never included the name of the maker of the constitution. All the media of communication had been unable to inform people like me about this name.(Ibid, p.83)

The life struggle of Ambedkar shook him completely and he described that impact thus:

There was nothing special in the opening pages. But the further I went into the book, I felt as though a new chapter about life was being unfurled before me a chapter about which I had known nothing. Dr. Ambedkar('s) life long struggle 
had shaken me up. I spent many days and nights in great turmoil. The restlessness inside me had increased. My stone-like silence began to melt. I proceeded to read all of Ambedkar's books that I found in the library. (Ibid, p.83)

That soul-stirring effect led to his active participation in the social and political life of the college. Literature on Ambedkar was used by Valmiki at the 'deliberate' level of reflexivity as he actively searched for other works of Ambedkar and started using them as a resource. In this process, Valmiki's identity got its unique dimension: 'A new word, Dalit entered my vocabulary; a word that is not the substitute for 'Harijan', but an expression of rage of millions of untouchables. A new direction was opening for me...The deeper I was getting in(to) this literature the more articulate my rage became' (Ibid, p.84). Valmiki started debating with his friends on contemporary issues and became politically active. He witnessed the life of Dalits closely while canvassing for his friend in Roorkee. Now reality unfolded itself in its multitude of dimensions as he acquired the lens of Ambedkarism. He writes,

The canvassing provided me with the opportunity to see the lives of people at close range. I heard the stories of deprivation. Most of the people did not understand the true meaning of democracy or the value of one's vote. They couldn't grasp the importance of stuffing a piece of paper in the ballot box. How innocent were these people. But then, had independence truly reached them? The pimps of the rulers were exploiting them for their own ends. (Ibid, p.86)

As part of these transitional processes, he could see the power structure operating under the veil of caste system. He relocated to different places after Dehradun, and after each relocation he ended up in a different frame of activity but the transitions continued. Each frame of activity brought forth a more sharply redefined identity, more knowledge and skills, and new ways to understand the world with the intellectual prism of Ambedkar.

He joined the ordnance factory Dehradun as an apprentice and for that he had to give up higher education. Books, again, proved to be his best friends that boosted his morale at this stage. After the one year training at Ordnance Factory Dehradun, he got an opportunity of further training in Jabalpur. Those were the days, according to him, when his selfhood was getting built. 'The new surroundings and the new environment gave him new experiences' (Ibid, p.97). His social circle widened as he came in touch with people from diverse backgrounds in Jabalpur, especially, when he shared his room with boys who hailed from completely different backgrounds. These roommates were from Dehradun, Muradnagar, Kanpur, and Pune.

Ambedkar's writings already had an influence on him and here in Jabalpur after coming in the contact of students having interest in Marxist literature, he accessed Marxist readings as well. He developed an interest in theatre and, finally, started writing poetry.

There were some students who had Marxist leanings, and I started to read Marxist literature after coming into contact with them. Gorky's Mother, especially, shook me up. I had also become acquainted with Chekhov's short stories. I joined these Marxists in forming a theatre group. We rehearsed in the hostel. We staged many plays in the Institute's auditorium. (Ibid, p.98)

Valmiki's personality, speech patterns, and manners underwent major changes. The transformation of identity was facilitated by the social network he formed there. His social network consisted of people who were primarily interested in contemporary issues. The cognitive resources were provided by the seminars and cultural functions 
he attended. And most importantly, symbolic resources, here especially the work of anti-caste intellectuals, enabled the distancing process and he started developing his own views on literature. He was 'more attracted to social realism than to aesthetic and formalist type of writings' (Ibid, p.99). By now he had started using symbolic resources at the highest level of reflexivity'- reflective usage.

The most important relocation occurred when he moved to Bombay (now Mumbai) for further training of two and a half years. This was the place and time which led to the most significant transitions in Valmiki's life. At Ambernath Hill where he received his training, he read Pasternak, Hemmingway, Victor Hugo, Pierre Louis, Tolstoy, Pearl Buck, Tugenev, Dostoevsky, Stevenson, Oscar Wilde, Romain Rolland, and Emile Zola. He also read the entire works of Rabindranath Tagore and Kalidasa here. He met people from different backgrounds and states and got more interested in theatre which, subsequently, became a regular weekend activity for him. He also started a drama group in the hostel. He wrote his first essay on the problems of Dalits which became a point of controversy. Most importantly, he started reading Marathi Dalit literature which actually broadened his consciousness, already made critical by the works of Ambedkar and Phule.

It was during these days that I was introduced to Marathi Dalit literature. Dalit writings were changing the face of Marathi literature. The words of Daya Pawar, Namdev Dhasal, Raja Dhale, Gangadhar Pantavane, Baburao Bagul, Keshav Meshram, Narayan Surve, Vaman Nimbalkar and Yashwant Manohar were igniting sparks in my veins. Their voices exhilarated me, filled me with new energy. My reading of Dalit literature was beginning to change my notions about what is literature.(Ibid, p.105)

The process of transition acquired a new direction when he started participating in the Dalit movement after getting appointed at the Ordnance Factory, Chandrapur. It was the time he started writing and also started a theatre group named Meghdoot Natya Sanstha (Meghdoot drama institute). His poems were published in magazines such as Navbharat, Yugharm and NaiDuniya. He also started writing a column in Janapratinidhi, a Chandrapur Weekly. Moreover, Dalit movement and Buddha's philosophy continued to influence his consciousness at that time.

I came across the marvelous glow of Dalit consciousness. The self-fulfillment that I experienced in connecting with the Dalit movement was truly a new experience for me. The deeper my involvement became with the movement, the further many of my friends moved away from me. In their eyes I had wandered away from the right path and was bent on destroying my talent and creativity... Buddha's philosophy on human freedom had attracted me. He says that there is no such thing as the unchangeable in a constantly changing universe. The human being alone matters. It is Karuna (compassion) and wisdom that takes a person towards transcendence.(Ibid, p. 116)

The reconfigured semiotic prism (Figure 2) provides the nuanced understanding of the process of redefined identity of Valmiki as a Hindi Dalit writer. ${ }^{4}$ The crucial contribution comes from the social network that he developed and drew motivation from after each relocation. He mobilized his wide knowledge of Hindi and Marathi Dalit literature and also his theatrical capabilities as significant cognitive resources. Coming to the most 
crucial of all, the cultural elements that Valmiki mobilized as symbolic resources were the works of Ambedkar and Phule as well as Marxist writings.

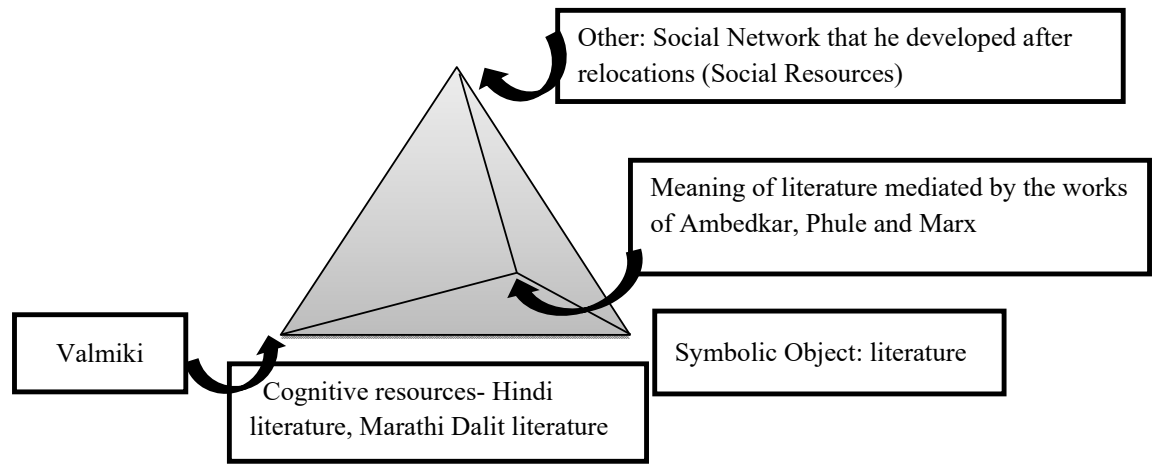

Fig. 2: Reconfigured Semiotic Prism Followed by Relocations

The essence of the symbolic resources was not lost in the process of creation but utilized by Valmiki at the 'reflective' level of reflexivity. Rather, the capability of distancing was eased by the works of Ambedkar, Phule, and Marx. Beyond the immediate cultural value of symbolic resources, he created characters on the plane of fiction. That's why his characters are infused with Dalit consciousness even without making any direct reference to the ideas of anti-caste intellectuals. His stories are inscribed in time as they connect past with the present and weave the realities and subtleties of caste in the village and city simultaneously. Significance of their creation lies in the fact that even the fictional characters are portrayed against the reality of the caste-ridden Indian society.

\section{Conclusion}

To conclude, life is to be seen in all its complexities to capture its essence. The resources and transitional processes discussed here are not independent; rather they work as a unified whole and what comes out of their amalgamation is a distinct collective identity that cannot be broken down into the very elements it emerged from. This identity is continuously reified, subjected to deconstructions and reinterpretations. At the highest level of reflexivity the social position sanctioned in social ladder against the backdrop of the caste-ridden society is itself used as a symbolic resource. That's why writers like Valmiki, 'transform this position symbolizing the internalised oppression into an emblem of dissent. They utilize the abhorrence contained in this social position as a weapon to challenge this position. This transformation enables them to imagine a novel and imaginary world of equality amidst the caste-ridden society' (Vyas \& Panda, 2019, p.125). And what emerges as a result is the dynamic collective identity of a Dalit writer.

\section{References}

Brueck, L.R. (2014). Writing resistance: the rhetorical imagination of Hindi Dalit literature.

New York: Columbia University Press.

Gergen, K.J. (1999). An invitation to social constructionism. London: Sage. 
Hunt, S. B. (2014). Hindi Dalit literature and politics of representation. New Delhi: Routledge.

Kumar, R. (2010). Dalit literature: a perspective from below. In I. Ahmed \&S.B. Upadhyay(Eds.), Dalit assertion in society, literature and history (p. 121-136). New Delhi: Orient BlackSwan Private Limited.

Limbale, S.K. (2004). Towards an aesthetic of Dalit literature: history, controversies and considerations (trans. A. Mukherjee). New Delhi: Orient Blackswan Private Limited.

Limbale, S.K. (2007). Akkarmashi- The outcaste (trans. S. Bhoomkar). New Delhi: Oxford University Press.

Valmiki, O.P. (2001). Dalit SahityakaSaundaryashastra. New Delhi: Radhakrishna Publications.

Valmiki, O.P. (2003). Joothan. Trans.by Arun Prabha Mukherji. Kolkata: Samya Publication.

Valsiner, J. (2014). An invitation to cultural psychology. New Delhi: Sage Publication.

Vyas, A. and Panda, M. (2019). Reification of collective victimhood: Dalit narratives, social repositioning and transformation. Psychology and Developing Societies, 31(1), 106-138. New Delhi: Sage Publication.

Zittoun, T. (2007a). The role of symbolic resources in human lives.In J. Valsiner\& A. Rosa (Eds.), The Cambridge handbook of sociocultural psychology (pp. 343-361). Cambridge: Cambridge University Press.

Zittoun, T. (2007b). Symbolic resources and responsibility in transitions. Young, 15(2), 193-211.

Zittoun, T. (2008). Learning through transitions: the role of institutions. European Journal of Psychology of Education, 23(2), 165-181.

\section{Endnotes}

1 The present paper is a modified extraction from the M.Phil dissertation titled 'Caste, experience and creativity: a cultural psychological analysis of the life and literature of Om Prakash Valmiki' by the author submitted to Zakir Husain Centre for Educational Studies, Jawaharlal Nehru University in July 2015.

2 The terms denoting social hierarchy like upper and lower have been used to refer the stratified caste structure of the society, only to maintain the readability of the text wherever it is necessary. The author does not subscribe or encourage the usage of such terms.

3 An ancient Sanskrit maxim that Truth (Satya), God (Shiva) and Beauty (Sundara) are the three manifestations of the same primordial entity. It is translated as Truth (absolute) is God, which is auspicious or holy (the essence which permeates the universe) and God is beauty (that which rejuvenates).

4 Brueck (2014) also elaborates on the three specific features of Hindi Dalit writing namely, social realism, melodrama and heteroglossia. Valmiki's use of literary rhetoric in his writings is driven by cognitive resources. Standard Hindi that he uses to portray Dalit consciousness was acquired through an in depth study of mainstream Hindi literature. He talks about his bent towards social realism in his autobiography. The aesthetic convention of melodrama can be attributed to his experience resulting from his involvement in theatrical activities in the city.

The Study by Hunt (2014) also substantiates the understanding of the dimensions of the prism. She points out that the genres chosen by Hindi Dalit writers to present their writings are those that are accepted in the field of Hindi mainstream literature and contain more symbolic value as compared to the works of Hindi Dalit pamphlet writers. She considers it as one of the agreed upon strategy by members of the Hindi Dalit literary sphere. In the context of the prism, these writers can be placed at the top of the prism in the category of 'Other'. Thus, socially shared meaning of Dalit literature now also influenced and got influenced by Valmiki's sense of Dalit literature. 